\title{
Standards as a tool for quality management in the pipe market
}

\author{
Ekaterina Ogorodnikova ${ }^{1}$, Ludmila Creciun $^{2}$, Alexandr Kokovikhin ${ }^{3}$ and Ruslan \\ Dolzhenko $^{3^{*}}$ \\ ${ }^{1}$ Ural State University of Economics, Department of Management, 8th March str. 62, Ekaterinburg, \\ Russian Federation \\ ${ }^{2}$ Banca de Finante si Comert SA, Pushkin str. 26, Chisinau, Moldova \\ ${ }^{3}$ Ural State University of Economics, Department of Labour Economics and Human Resources, 8th \\ March str. 62, Ekaterinburg, Russian Federation
}

\begin{abstract}
In the production of large diameter pipes, quality standards are a new tool of struggle in the international market. Management systems that meet the requirements of international standards, for enterprises act as a tool that, in the process of interacting with the external environment, is able to adapt and adequately rebuild the activities of the enterprise. The purpose of the article is to analyze the application of standards in pipe plants as a tool for quality management.
\end{abstract}

\section{Introduction}

In modern conditions, the demand for the pipe market is formed under the influence of a complex set of different factors, the dynamism and variety of which require the construction of an adequate quality management system (QMS).

Satisfaction of all market participants is realized through management functions, developed on the basis of international standards, defining the requirements for the management systems of organizations and opening up new markets for the global economy. Widely known ISO 9000 standards summarized the world's best practices and requirements in the field of production management [1], [2], [3]. In Russia, in turn, similar national standards were introduced: GOST R ISO 9000-2008, GOST R ISO 9001-2011, GOST R ISO 9004: 2010.

As practice shows, management systems that meet the requirements of international standards, for Russian enterprises act as one of the main tools that can provide the process of work in the international markets by adapting the internal processes of the enterprise.

The most common methods for assessing the implementation of quality standards in the pipe industry are the EFQM model [4], the Tito Conti self-assessment method [5], the FMEA analysis [6] and the balanced scorecard (BSC) system [7]. There are also developed some new approaches to assessing the application of quality standards, including a market assessment of the company's activities [8], [9], [10].

\footnotetext{
* Corresponding author: $\underline{\mathrm{cmb} 8 @ \text { mail.ru }}$
} 


\section{Methods}

Within the framework of this article, the index rating of performance evaluation (MINOR) model will be used to determine the results of using the quality standards of the Russian pipe market enterprises and their impact on achieving the objectives of competition in the international market. Briefly, we present the essential characteristic of this model and its main steps are shown in Figure 1.

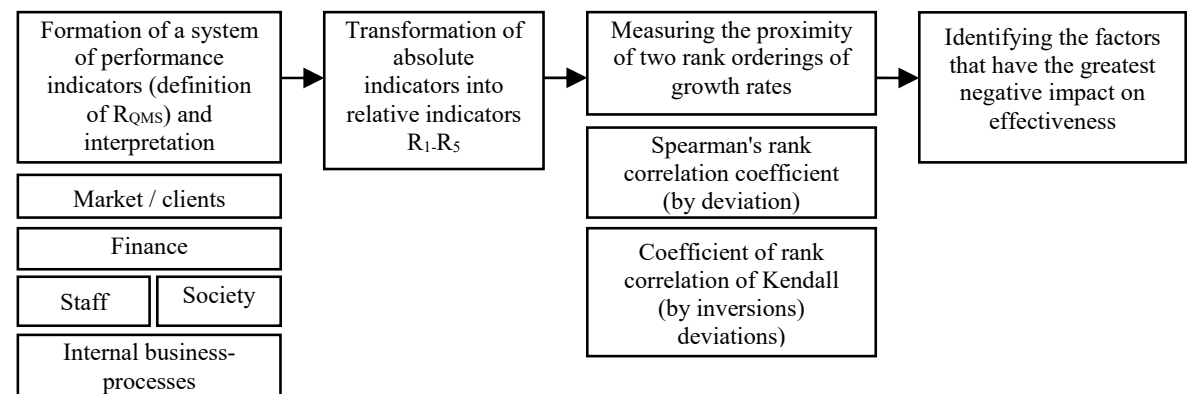

Fig. 1. Stages of the procedure for evaluating the effectiveness of the enterprise's quality management system.

The first stage of the model assumes the formation of a system of performance indicators in the context of the main strategic directions of the organization's development. It is necessary to emphasize the importance of assessing the market performance of the organization's activities in the market and the results that it has achieved with respect to the satisfaction of the interests of external consumers.

At the second stage of the procedure, absolute values are converted into relative values, namely, to the chain growth rates of these indicators and their compliance with priorities set by the company's management, based on the principle of the growth rate of this indicator in the system. Thus, the task of dynamic assessment of the use of quality standards is being solved.

At the third stage of the methodology implementation, the proximity of two ranks ordering of growth rates is determined, using Spearman's rank correlation coefficients (by deviations) and Kendall's (by inversions). With the help of these coefficients, it is possible to estimate the proximity of one ranking series to another, taken as a standard, in the interval from +1 to -1 [11]. The generalized performance score obtained on the basis of two correlation estimates is determined by the following formula:

$$
R=\frac{\left(1+R_{d e v}\right) \times\left(1+R_{i n v}\right)}{4},
$$

Where: $R_{d e v}$ - the coefficient of rank correlation by deviation;

$R_{i n v}$ - the coefficient of rank correlation by inversions.

The coefficient $R$ varies in the range from 0 to 1 . The coincidence of the actual order and the order of indicators specified in the dynamic norm proves the highest level of realization of the goals of using the standards.

Positive values of estimates of these correlation coefficients characterize a regime of the system in which the level of realization of the function continues to grow. The negative values of the same estimates reflect the situation when the system mode begins to act against the level of the function's implementation, i.e. reduce it. The estimate, constructed on the deviations, characterizes the volume side of the change in effectiveness in this mode. 
The volume side of the function of the quality standard expresses the quality of the activity as a specific and independent sign of the operating mode of the whole system. The evaluation, built on inversions, determines the structural dynamics of the company's final results. Evaluation of the structural side of the standard shows the effectiveness of the compared regimes.

In order to make a meaningful interpretation of the obtained data on the effectiveness of the QMS, it is necessary to normalize the positive component of the overall performance on the interval $[0.25 ; 1]$ using the following formula:

$$
R^{*}=\frac{R_{i}-R_{\min }}{R_{\text {max }}-R_{\text {min }}} \times 100,
$$

Where: $R^{*}$ - the secondary normalization value of $R_{i}$;

$R_{i}$ - the value of the performance factor, subject to secondary rationing;

$R_{\max }$ and $R_{\min }$ - the maximum and minimum values of the performance coefficient on the normalized interval, respectively.

The fourth stage in the analysis of effectiveness is the identification of factors that have the greatest negative impact on the effectiveness of the organization.

To determine the critical indicators, the method of isolated influence of factors on the change of the effective indicator is used. In the QMS performance measurement model, it is envisaged that the dynamics of the factor indicators are maintained either at the normatively established level or below it, so the generalized assessment of the effectiveness of the QMS is based on a comparison not with the actual (past) state, but with the ideal - normatively established. In this regard, the influence of factors is assessed by the extent to which they have lowered the evaluation of the effectiveness of the QMS compared to the ideal.

In other words, the factors do not decompose the actual performance assessment itself, but the difference between the maximum and actual estimates as follows:

$$
\Delta R\left(K_{i}\right)=R_{s}-R\left(K_{i}\right)
$$

Where: $\Delta R\left(K_{i}\right)$ - the decrease in the evaluation of performance under the influence of the $i$ th indicator;

$R_{s}=1-$ an estimation of reference performance of QMS;

$K_{i}$ - the indicator occupying the $i$-th place in the dynamic norm;

$R\left(K_{i}\right)$ - an evaluation of performance, calculated only on the basis of the dynamics of the $i$-th indicator.

For greater visibility and ease of use, the share of the influence of each indicator on the overall decline in the level of effectiveness is calculated by the formula:

$$
\delta_{i}=\frac{\Delta R\left(K_{i}\right)}{\sum_{i=1}^{n} \Delta R\left(K_{i}\right)} \times 100,
$$

Where: $\delta_{i}$ - the share of influence of each indicator on the overall decline in the level of effectiveness; th indicator.

$\Delta R\left(K_{i}\right)$ - the decrease in the evaluation of performance under the influence of the $i$ -

For a graphic representation of the relative importance of the factors that caused the deviations, we can use the Pareto diagram, which is constructed on the basis of the deviation values of each annual performance indicator calculated by formulas (3), (4). 


\section{Results and analysis}

Russian steel pipe producers are mostly oriented to the domestic market, supplying domestic consumers with more than $80 \%$ of the output. The core of the Russian pipe industry are the three holding companies - the Pipe Metallurgical Company (TMK), the Chelyabinsk Tube Rolling Plant (CHTPZ), the United Metallurgical Company (OMK), which until recently provided up to $70 \%$ of the domestic market needs. In recent years, due to the modernization of capacities and the launch of new production facilities, the supply on the market has increased, which has led to increased competition.

At present, there are two alternative standards for pipes for main pipelines in the industry, differing in the principles of classifying pipes according to strength classes and quality categories: GOST 31447-2012, based on Russian classification principles, and GOST ISO 3183-2012, identical to the international standard ISO 3183: 2007. An example of a normative document at the federal level that partially eliminates these contradictions is the new GOST R 56403-2015, relating to the main transport of oil and petroleum products. GOST R 56403-2015 is developed on the basis of Russian approaches to assessing the strength and principles of pipe classification, which is especially important in the context of the import substitution policy implemented in Russia.

Consider the application of the above methodology on the example of JSC "STZ", the largest participant in the pipe industry, which is part of the TMK group of companies. The enterprise's products are supplied to both Russian and foreign consumers. Pipes are produced according to state standards, technical conditions, API, ASTM, DIN standards. The total capacity of all TMK's plants for the production of pipes of various assortments is about $50 \%$ of the total production capacity of the Russian pipe complex.

In the history of development of the quality system of JSC "STZ" there are several stages:

- the first stage (late 50's - early 70's) - the creation of a quality control system;

- the second stage (late 70's - early 80's) - the creation of a comprehensive product quality management system, the functioning of which allowed to consistently improve technology and control;

- the third stage (from the beginning of the 90's) - the preparation of certification of the system and products for compliance with the requirements of international standards ISO 9001, API standards;

- the fourth stage - the certification of the management system for compliance with the requirements of international standards ISO 14001, OHSAS 18001.

After carrying out work on the development and implementation of the integrated management system in 2006, JSC "STZ" certified the management system for compliance with the requirements of international standards ISO 9001.

Certification audit was carried out at all declared facilities in accordance with the certification area, the end of which was confirmation by the independent certification body of compliance of the TMK Group with the requirements of the international standard ISO 9001.

The enterprises of the TMK Group received an umbrella certificate - a certificate confirming that the quality management system of all of the holding companies operates according to the same rules and covers all the processes that affect the quality that are realized in the various business units of the holding.

The quality management system operating at JSC "STZ" currently meets the requirements of international standards ISO 9001, GOST R ISO 9001, API Spec Q 1, ISO 14001, OHSAS 18001, applicable legislative and other regulatory requirements.

In the course of this study, the plant's performance indicators were analyzed, reflecting the impact of the use of quality standards on competitiveness of JSC "STZ" (Table 1). 
Table 1. Performance indicators for the use of quality standards.

\begin{tabular}{|l|c|c|c|c|}
\hline \multicolumn{1}{|c|}{ Index } & Deviation & $\begin{array}{c}\text { Cumulative } \\
\text { deviation }\end{array}$ & $\begin{array}{c}\text { Percent of } \\
\text { discrepancies }\end{array}$ & $\begin{array}{c}\text { Cumulative } \\
\text { percentage of } \\
\text { discrepancies }\end{array}$ \\
\hline $\begin{array}{l}\text { The ratio of the number of discrepancies detected in } \\
\text { internal audits that require correction or corrective } \\
\text { action, to the number of potential discrepancies, \% }\end{array}$ & 0,31 & 0,31 & $38 \%$ & $38 \%$ \\
\hline $\begin{array}{l}\text { Number of repeated notifications of consumers to the } \\
\text { total number of notifications, } \%\end{array}$ & 0,101 & 0,411 & $12 \%$ & $50 \%$ \\
\hline $\begin{array}{l}\text { Increase in customer satisfaction by factors related to } \\
\text { the activities of the enterprise. }\end{array}$ & 0,122 & 0,533 & $15 \%$ & $65 \%$ \\
\hline $\begin{array}{l}\text { Cases of registration of quality certificates for } \\
\text { products in violation of established requirements } \\
\text { compared to the last year, \% }\end{array}$ & 0,12 & 0,653 & $15 \%$ & $80 \%$ \\
\hline $\begin{array}{l}\text { Increase in customer satisfaction with the factor } \\
\text { "product presentation",\% }\end{array}$ & 0,036 & 0,689 & $4 \%$ & $84 \%$ \\
\hline $\begin{array}{l}\text { Reducing the number of recurring inconsistencies } \\
\text { identified during the production control of the 2nd } \\
\text { stage, } \%\end{array}$ & 0,035 & 0,724 & $4 \%$ & $89 \%$ \\
\hline $\begin{array}{l}\text { Compliance with the Generalized Metal Coefficient, } \\
\%\end{array}$ & 0,034 & 0,758 & $4 \%$ & $93 \%$ \\
\hline $\begin{array}{l}\text { The ratio of the number of new products contributed } \\
\text { to the specialization of the plant to the number of new } \\
\text { products planned in the Program for the Development } \\
\text { of New Types of Products, } \%\end{array}$ & 0,023 & 0,781 & $3 \%$ & $96 \%$ \\
\hline $\begin{array}{l}\text { Increase in percentage of implemented } \\
\text { recommendations for improvement of activities } \\
\text { compared to the last year,\% }\end{array}$ & 0,011 & 0,792 & $1 \%$ & $97 \%$ \\
\hline $\begin{array}{l}\text { Degree of implementation of the decisions of the } \\
\text { previous analysis of the implementation of quality } \\
\text { standards by management, \% }\end{array}$ & 0,011 & 0,803 & $1 \%$ & $98 \%$ \\
\hline \begin{tabular}{l} 
Other \\
\hline
\end{tabular} & 0,013 & 0,816 & $2 \%$ & $100 \%$ \\
\hline
\end{tabular}

Based on the compiled performance table, the Pareto chart was also constructed according to the method presented above (Figure 2).

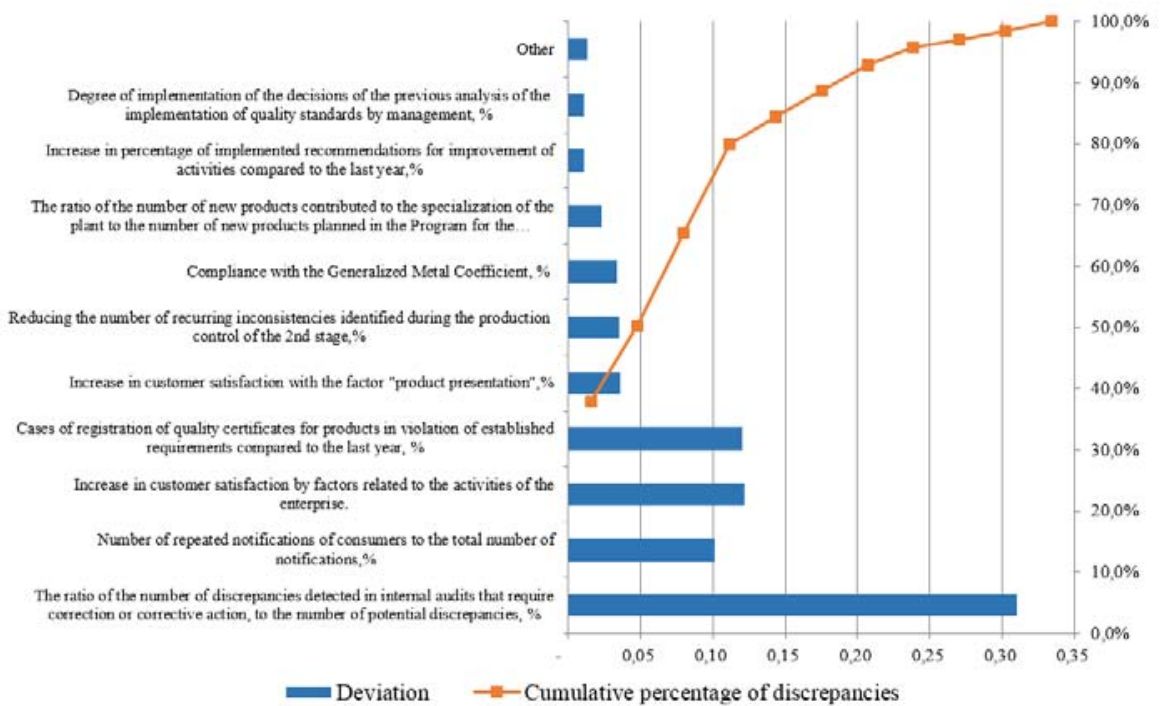

Fig. 2. Ranking of QMS performance indicators. 


\section{Conclusions}

The proposed model makes it possible to identify critical areas of the enterprise, which directly affect the quality of products and the competitiveness of the enterprise. At the level of such systems as holdings and vertically integrated financial and industrial groups, the model can be used for conducting comparative management analysis.

The system of aspiration to the ideal used in this methodology may prove ineffective, since the image of the ideal can be very different in the minds of different managers of the same organization. Also in this methodology, the process approach is not taken into account.

The conducted research on the basis of the index rating of performance evaluation model shows the main zone that determines the deviations of performance indicators from those given in the quality standards. The ratio of the number of discrepancies detected in internal audits requiring correction or corrective action to the number of potential discrepancies is $31 \%$.

This approach is realized within the framework of the general methodology of quality management in the pipe industry given in works from [2] to [5]. This methodology allows Russian pipe companies to maintain a sufficient level of competitiveness and influence the achievement of competition in the international market.

\section{References}

1. I. Guler, M.F. Guillén, J. Muir, and others, Adm. Sc. Q. 47 (2), 207 (2002)

2. A.N. Schmeleva, Qual. Acc. Suc. 18 (160), 100 (2017)

3. L. Ilies, H.C. Salagean, I. Beleiu, Amf. Ec. 19 (SE 11), 1050 (2017)

4. J.C. Bou-Llusar, A.B. Escrig-Tena, V. Roca-Puig, and others, J. Op. Man. 27 (1), 1 (2009)

5. T. Conti, TQM J. 22 (4), 352 (2010)

6. H. Arabian-Hoseynabadi, H. Oraee, P.J. Tavner, Int. J. El. Pow. En. Sys. 32 (7), 817 (2010)

7. Z. Hoque, Cr. Per. Acc. 14 (5), 553 (2003)

8. G. Guandalini, P. Colbertaldo, S. Campanari, Appl. En. 185, 1712 (2017).

9. Oil Gas J. 115, 11A (2017).

10. E.S. Gorkunov, S.M. Zadvorkin, E.A. Putilova, and others, Inorg. Mat. 52 (15), 1483 (2016)

11. E. Szmidt, J. Kacprzyk, EUSFLAT 1 (1), 521 (2011) 